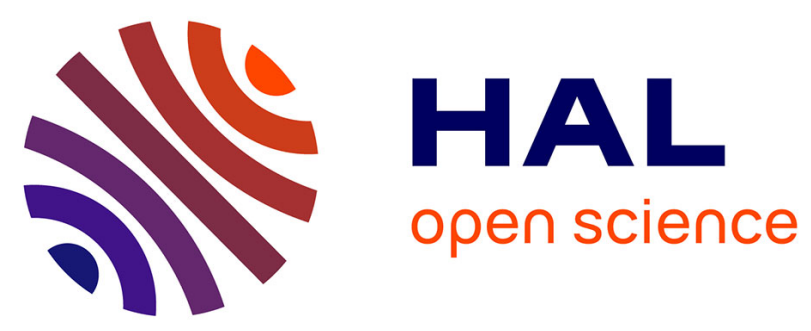

\title{
Technological Services in Shared Housing: Needs Elicitation Method from Home to Living Lab
}

P. Rumeau, Nadine Vigouroux, Eric Campo, Elizabeth Bougeois, Frédéric

Vella, Adrien van den Bossche, T. Val, J. Ancilotto

\section{To cite this version:}

P. Rumeau, Nadine Vigouroux, Eric Campo, Elizabeth Bougeois, Frédéric Vella, et al.. Technological Services in Shared Housing: Needs Elicitation Method from Home to Living Lab. Innovation and Research in BioMedical engineering, 2021, 42 (2), pp.73-82. 10.1016/j.irbm.2020.06.013 . hal-02930354

\section{HAL Id: hal-02930354 \\ https://hal.science/hal-02930354}

Submitted on 2 Jan 2021

HAL is a multi-disciplinary open access archive for the deposit and dissemination of scientific research documents, whether they are published or not. The documents may come from teaching and research institutions in France or abroad, or from public or private research centers.
L'archive ouverte pluridisciplinaire HAL, est destinée au dépôt et à la diffusion de documents scientifiques de niveau recherche, publiés ou non, émanant des établissements d'enseignement et de recherche français ou étrangers, des laboratoires publics ou privés. 


\title{
Technological services in shared housing: needs elicitation method from home to living lab
}

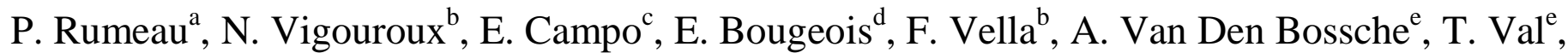 \\ J. Ancilotto ${ }^{d}$
}

\author{
${ }^{a}$ Laboratoire de Gérontechnologie La Grave, Gérontopôle, CHU de Toulouse, et UMRI027 Inserm-Université Paul Sabatier, \\ Toulouse, France \\ ${ }^{b}$ IRIT, UMR CNRS 5505, Université Paul Sabatier, 118, Route de Narbonne 31062 Toulouse, France \\ ${ }^{c}$ LAAS-CNRS, Université Toulouse Jean Jaurès, 7, Avenue du Colonel Roche, 31400 Toulouse, France \\ ${ }^{d}$ LERASS, Université Paul Sabatier, 115, Route de Narbonne, 31077 Toulouse, France \\ e IRIT, UMR CNRS, Université Toulouse Jean Jaurès, 5 Allée Antonio Machado, 31100 Toulouse, France \\ ${ }^{d}$ Ages Sans Frontières, Rue Caraven Cachin - 81630 Salvagnac, France
}

Reçu le ...; Reçu sous la forme révisée le ...; Accepté le ...

Disponible sur Internet le ...

\begin{abstract}
Housing under a shared housing organisation enables frail elderly persons to live in a semi autonomous way, thanks to cooperation between residents and an assistant. The social organization of this new type of housing also has an impact on the social participation of users. This article is based on a pilot study and deals with the benefits of digital technologies and « ambient intelligence » used to answer the needs of such a way of living.

The pilot study was carried out in a house shared by 6 co-tenants. The qualitative method used first consisted in a characterisation of the 6 inhabitants. This was followed by semi-structured interviews about their sensed needs, and a focus group, with 5 of the 6 cotenants, in order to gain an initial consensus about needs.

This result was confronted to the demands of the assistants, collected through interviews. A usage scenario was developed in a smart home (Maison Intelligente de Blagnac). This scenario was performed by three of the inhabitants and followed by a second focus group and a narrative interview with the assistants and the designers of the shared house. This article reports the method which was carried out and the needs expressed by the co-tenants.
\end{abstract}

Keywords: shared housing, elderly, needs elicitation method, living lab, technological services 2019 Elsevier Masson SAS. All rights reserved.

\section{Introduction}

In France, $41 \%$ of the persons living at home and receiving a Personal Independence Payment Funding is awarded to those with a significant handicap measured with a GIR (Iso Resource Group scale) ${ }^{1}$ lower or equal to $3^{2}$ (meaning they are handicaped in their daily duties both at home and outdoors). The onset of handicap often results in living in housing structures for dependant elderly people. According to The WHO International Classification of Functioning ${ }^{3}$, the loss of social participation is closely linked with deficiency. The social organization can either facilitate or inhibit social participation. In the current context of the alternative housing initiatives for the elderly [1], these housing forms have in common the value of social integration, but this is variously achieved. The concept of housing can increase a dual social representation with, on the one hand, ordinary housing for the autonomous elderly population, and on the other hand, collective housing for the frail or dependent population.

The existing offer of home care support or social nursing accommodation: nursing homes (EHPAD) ${ }^{4}$, other retirement homes, family homes or the commercial offer for the elderly (senior citizen's residence...) is not enough to prevent handicap. Thus, on our territories, the elderly often face a dilemma: staying at home, withing a familiar environment, however facing the fear of becoming disabled or leaving home and going to a retirement home or institution and fearing to lose independence. In rural territories, frail older people face:

- The decrease of family solidarity and neighbourly relations;

- Solitude and /or social isolation;

- The loss of local services (care, shopping facilities, public services);

- Low income compared to the cost of assistance or accommodation services;

- Too expensive retirement homes for families who do not wish to mortgage the family property (rural culture).

\footnotetext{
${ }^{1}$ https://www.pour-les-personnes-agees.gouv.fr/beneficier-daides/lallocation-personnalisee-dautonomie-apa/comment-le-gir-est-ildetermine

${ }^{2}$ http://www.urbanisme-puca.gouv.fr/IMG/pdf/note_at_viellissement_de_la_population_et_habitat.pdf

${ }_{3}^{3}$ World Health Organization. (2001). International classification of functioning, disability and health : ICF : short version, Short version. Geneva : World Health Organization.

${ }^{4}$ Etablissement d'Hébergement pour Personnes Âgées Dépendantes : litteraly elderly dependant peoples'home. 
Various studies carried out on interviews during field surveys have illustrated the extent to which these forms of housing based on social ties make it possible to break down solitude and isolation, and to give a meaning to one's life experience by sharing it with others. This is their primary goal, whatever the concept of housing proposed, more or less participative, more or less collective [2]. The image of the dependent elderly person being cared for in a specialised structure is replaced by that of a pensioner who chooses to keep control of his life and of his usual or new social networks. But the person has to accept the constraints of living in a community and who to cohabit with other social networks, already in place and with other needs that place him/her in a social inhibition position [1].

In 2008, an association, Âges Sans Frontières (ASF) $)^{5}$ created an alternative concept to the usual housing solutions on a shared housing organization. The inhabitants are co-tenants of a house equiped with support services and an assistant, who can provide mediation. The co-tenants support one another while still living in a private housing.

In accordance with the Aging Population and Habitat Workshop ${ }^{6}$, we have studied the «needs in terms of new technologies for residents in a shared home, in a rural area » within a True Live Lab (TTL) [3], a method of deployment of innovations which were codesigned in an «ecological» environment. The expression of the technology needs was first collected on-site, in the shared house of Montredon. It was then studied in depth in a monitored environment -Living-Lab type- the Blagnac Smart Home (Maison Intelligente de Blagnac), in order to put forward new technologies so that interactions between the person and his or her environment could be facilitated.

In this article, we will identify different types of housing for the elderly. Then, we will develop the shared housing concept designed by Âges sans frontières. The method of testing is next described on a pratical case. It consists of: 1) a series of narrative interviews, followed by a focus group with the co-tenants of the shared house, in Montredon (Tarn, France), 2) a visit of the Blagnac smart home and the performing of a usage scenario -based on the use of technological tools- by the residents of the shared house, and a second focus group.The results, in terms of needs and acceptability will be developped and discussed. Outlooks will be proposed.

\section{Senior citizens' housing}

In the work coordinated by P. Pitaud [4], he addressed the issue of loneliness experienced or felt as such, isolation and the physical and moral suffering that results from it. Clément et al. [5] studied the neighbourly relations of the elderly as a mean of overcoming some of the loneliness. In "La solitude du chez soi : Un territoire sans partage ", Campéon [6] discusses the link between loneliness and the type of housing.

Tab. 1. Desired living places in the case of loss of autonomy, by age [7].

- It would be desirable and realistic
It would not be desirable and realistic
It would be unthinkable

\begin{tabular}{|c|c|c|c|c|c|c|c|c|c|c|c|c|c|}
\hline \multirow[b]{3}{*}{ Stay in your current home by adapting it } & \multirow{2}{*}{\multicolumn{2}{|c|}{$\begin{array}{l}\text { TOTAL } 65 \text { years } \\
\text { and over }\end{array}$}} & \multicolumn{11}{|c|}{ BY AGE } \\
\hline & & & \multicolumn{2}{|c|}{$65-69$ years } & \multicolumn{3}{|c|}{ 70-74 years } & \multicolumn{3}{|c|}{ 75-79 years } & \multicolumn{3}{|c|}{80 and over } \\
\hline & 68 & 2110 & 68 & 2012 & 70 & 21 & 9 & 71 & 20 & 9 & 66 & 22 & 12 \\
\hline $\begin{array}{l}\text { Take accommodation alone or with my } \\
\text { partner in a more suitable residence } \\
\text { offering different services }\end{array}$ & 31 & 0 & 38 & 4121 & 31 & 44 & 25 & 27 & 44 & 29 & 26 & 41 & 33 \\
\hline Go to live in a retirement home & 54 & 37 & 9 & 5536 & 10 & 52 & 38 & 6 & 55 & 39 & 13 & 513 & 36 \\
\hline $\begin{array}{l}\text { Benefit from the help of a "companion" } \\
\text { robot }\end{array}$ & 14 & 45 & 15 & 4243 & 14 & 44 & 42 & 13 & 43 & 44 & 13 & 43 & 44 \\
\hline $\begin{array}{l}\text { Go to live with a relative who would take } \\
\text { care of you }\end{array}$ & 14 & 49 & 12 & $40 \quad 48$ & 9 & 36 & 55 & 16 & 34 & 50 & 20 & 36 & 44 \\
\hline $\begin{array}{l}\text { Living in an apartment that you would } \\
\text { share with others }\end{array}$ & $10 \quad 37$ & 53 & 13 & $\begin{array}{ll}38 & 49\end{array}$ & 8 & 36 & 56 & 8 & 35 & 57 & 11 & 36 & 53 \\
\hline
\end{tabular}

Source: Ipsos for the Korian Aging Well Foundation, 2016 Barometer

Loneliness together with economic insecurity can worsen the loss of autonomy. The type of housing can be aggravating. Senior citizens' housing varies according to their health profile, degree of autonomy, financial capacity, lifestyle or social life. $74 \%$ of people aged 65 and over own their own home [7]. To the question, "if tomorrow you became very dependent and had to benefit from medical

\footnotetext{
${ }^{5}$ https://www.agessansfrontieres.fr/

${ }^{6}$ DREES, Dossier Solidarité et Santé, N57, Décembre 2014. 
support and follow-up to survive, where would you like to live"? The answers are not so obvious but show the realism of the interviewees (see Tab. 1).

Not surprisingly, we find the clearly stated desire (around 90\%) to be able to stay at home as long as possible. Awareness of the possible consequences of ageing, and in particular concerns about loss of autonomy, has changed the relationship to home. Even if the need to adapt one's home is increasingly accepted, few people actualy do it.

In 2011, 7 out of 10 people over 85 years of age, compared to 1 out of 2 in 1982, were aging in their own homes, alone or in couples [7]. Nursing homes mainly accommodate very old (87 years on average) and very dependent (GIR 1 to 4) people and 96\% have neuropsychiatric conditions including $60 \%$ dementia [8]. Nowadays, elderly people are entering medico-social or even social institutions at higher levels of dependency than before. There is an attraction for structures providing private housing combined with personal services such as senior residences (about 600 such residences in France) or for residential housing renamed autonomyresidences (110,000 elderly people housed). Other solutions, with more empowerment in daily task of the residents, exist such as shared housing or collective homes ("babayagas", "beguinages"). These alternative living organizations, although still marginal or of local tradition, seem to be in progress (so far only 180,000 people out of 2 million people aged 85). They are most prevalent in areas close to city centres or in villages with a significant development potential. The question arises of collective living spaces that preserve the resident's participation while managing the tension between group and private life in order to overcome the dichotomy between home and institution.

Several new forms of housing have been identified, covering a multitude of concepts and designations [1]: service-homes, intergenerational housing, secure homes, community residences, foster homes, rental housing called "Papy loft", etc. Dominique Argoud proposes a typology based on five ideal types: "adapted housing" which benefits from accessibility, adaptability through new interior developments, domotization and new technologies, "serviced housing" : rental residences or full villages dedicated to the seniors with special services; "intergenerational housing" fighting the specialisation of spaces and places according to age, mixing their populations and encouraging intergenerational relations; "self-managed housing", in opposition to the institutional model of retirement homes. "Shared housing" allows pensioners to build, buy or rent a place in which they share a collective and mutual aid life, while preserving their autonomy. "Shared housing" promotes cohabitation either between a senior and a young person or between several elderly people. This housing brings together a collective that makes it possible to perpetuate the feeling of "home", to facilitate access to services (linen, cleaning, catering, and entertainment) and to promote social cohesion and solidarity between residents. It is also available to people with modest income and allows the persons to integrate into a particular territory [9]. Unlike self-managed housing, shared housing consists of a single room for each resident, while the kitchen, living room and possibly the bathroom are shared.

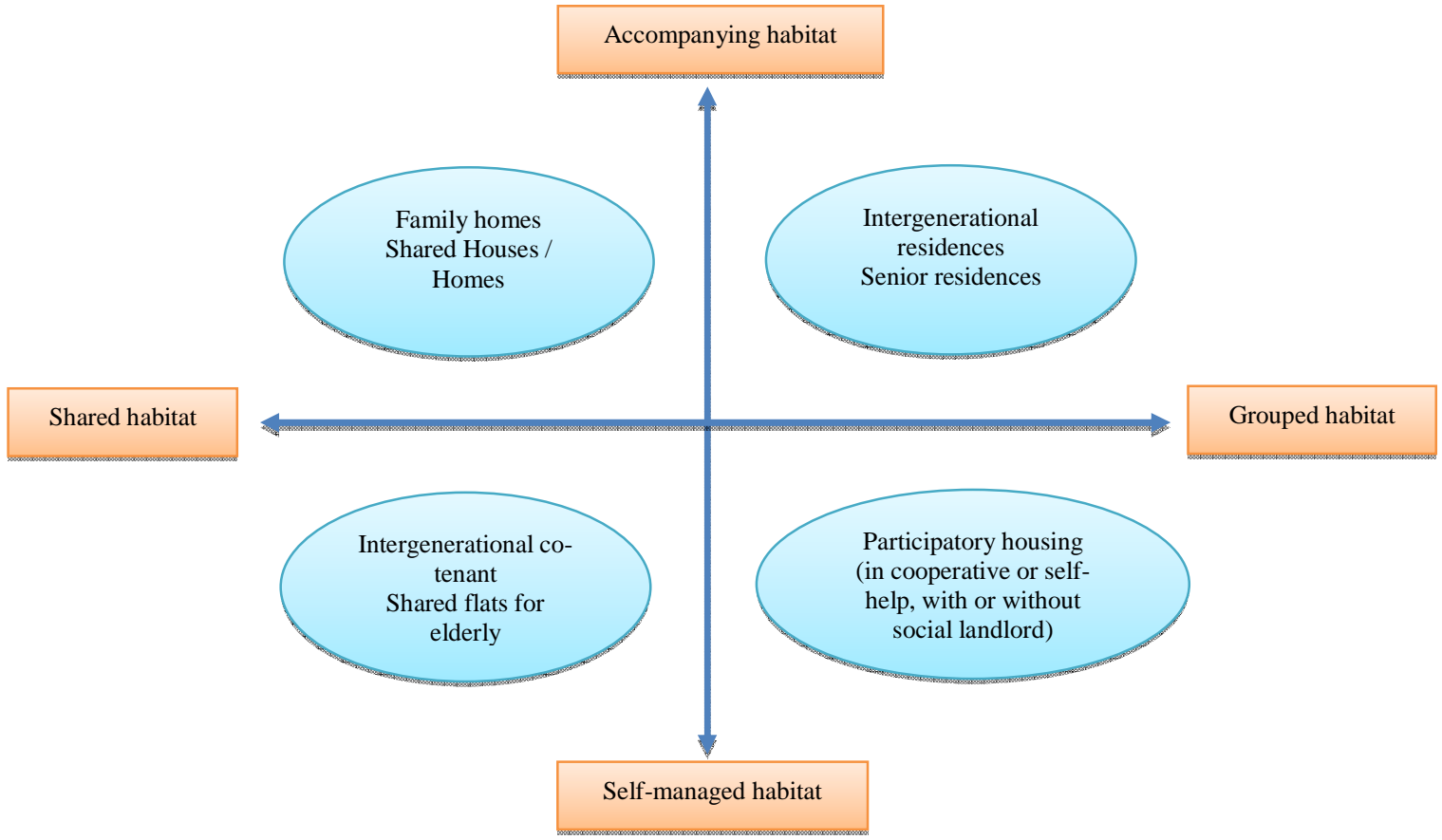

Figure 1. Typology of intermediate housing [2].

Nevertheless, we can see that, whatever their name, these habitats share the following characteristics: a grouped and functional individual habitat, a localization in a town centre or village centre, the accessibility and security of housing, integrated or close convivial spaces, the possible existence of services (whether outsourced or not), etc. It is also clear that the social integration and age 
mix dimension is highly valued in most of these new forms of housing (See Figure 1). These models of intermediate habitats between home and specialised institutions are not a first step to the nursing home, for the persons concerned, but really a substitute.

\section{ASF shared house used as a setting of the experiment}

The "ASF shared house" describes a shared house with a median position on the support habitat/self-managed housing [10]. Residents get support for cattering and benefit from an assistant who helps them organizing. They are in charge of household tasks and nightime safety. They get regular care from local primary care providers when needed.

Montredon is a small town in rural setting; the residents are of local origin. The shared house is for six residents. Each resident has a room en suite. Community areas include a common " $L$ "-shaped open space including a living room with a large-screen TV next to the main entrance, a kitchen in the middle, and a dining room. 4 residents have their room opening on this open space. The main open space communicates through a corridor to a smaller open space with a kitchenette and access to the rooms of the last two residents. The shared house is open to the town at the front and has a back garden that can be accessed from the two living rooms.

Each room has a landline cordless telephone, a television, a temperature control thermostat and an automatic light path to the bathroom. Both kitchen and kitchenette have an adjustable height worktop with button commands. There is no shared Internet access, computer or tablet. Residents may have their own digital equipment.

\section{Material and Method}

In this article, we want to propose a method of expressing needs that can be replicated in other shared habitats of the same type. This method consists in describing the population and its living conditions, and then the needs that these people express in these living conditions. The methodology is unconventional because we are dealing with each resident but who lives within a group of residents in the same house. The socio-technical approach must be adapted.

When we deployed our method, we had no idea of the population we were going to find. Its demographic characteristics were a first result of our study. We have therefore developed these results in a specific section of the article. We study a service that is the shared housing with a related organization; the users of the service may vary. The population is a variable, so it is also preferable, for the reproducibility of the study, to describe and discuss it in the results section. The study population is attached to the shared house of Montredon in the Tarn. It is composed of six residents and two assistants.

\subsection{Objectives of the study}

ASF wished to identify technological tools and services that could improve the service provided to residents of shared houses and optimize the action of their assistants. Our aim was to do so in an inductive and shared way, starting from the field (shared housing) and then specifying the needs through an adapted presentation and experimentation of the tools existing in the Blagnac smart home.

\subsection{Ethics}

The study we carried out was considered by the authors to be an observational study without significant risk to participants; it was not referred to a personal protection committee. Consent was obtained by the management staff of the shared house. The objectives of the study, the possibility of retracting at any time, the absence of any impact on the career development of the assistants and the level of support for the residents were specified.

Image rights were respected and people were able to refuse to be filmed. A consent form, corresponding to image rights, was given before each filmed step (focus group). The filming took place solely for analytical purposes, publication and non-profit use for scientific publications. It should be noted that, for methodological issues, people who did not wish to be filmed had to be excluded from focus groups. As a matter of principle, we have chosen to anonymize personal data (biographical data, interviews on uses, analysis and evaluation of daily activities).

\subsection{Study approach}

The method wich was deployed (See Figure 2) is composed of two phases. The first phase took place in the shared house of Montredon. It consisted of: 1) individual semi-structured interviews with the residents, then with the assistants 2) a focus group based both on the preliminary results of the semi-structured interviews with the residents.

The second phase took place in the Blagnac smart home [11] eight days later with three of the residents inculding: 3) a presentation of the Blagnac smart home automation and alarm functionalities, [12] including television control. Then the participants experienced the functionalities of the Blagnac smart home with tactile remote controle of the smart television and a scenario of morning rise 4) a focus group with the residents followed this experimentation phase.

Each of the residents and assistants had given their consent to participate in this study, consent was renewed oraly before each of the stages. 


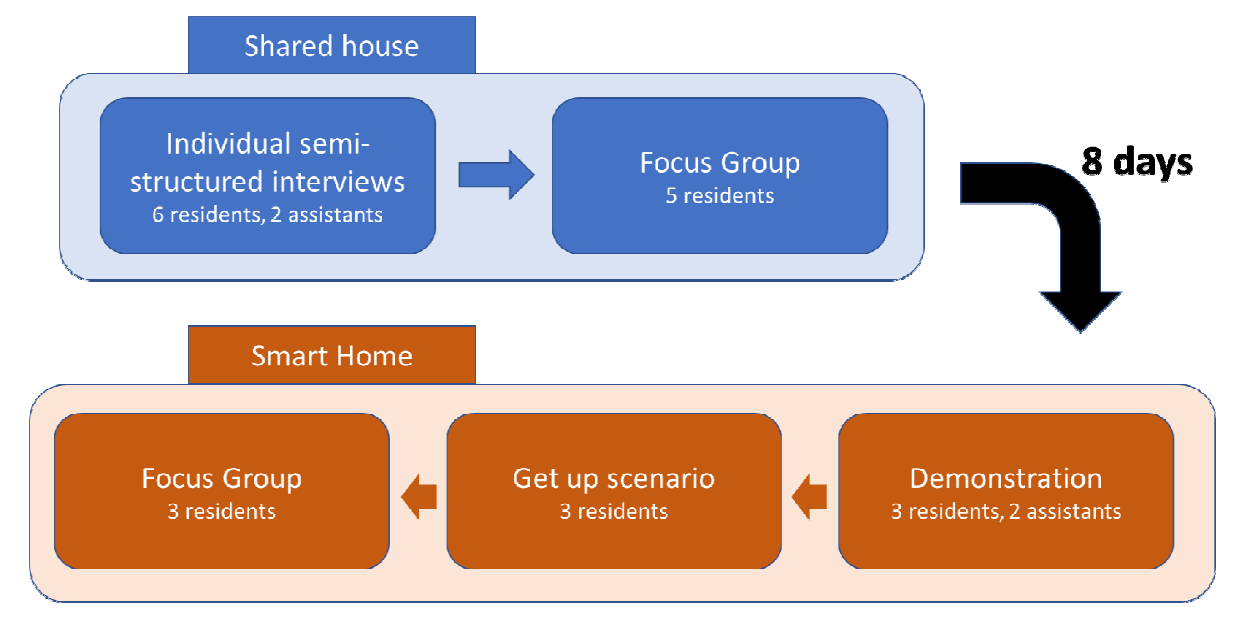

Figure 2. Diagram of the methodological process.

\subsection{Interview and focus groups within the Montredon shared house}

\subsubsection{Interviews and focus group with the residents}

The semi-structured interviews were carried out, face to face with the resident, in his or her room, either by a geriatrician trained in computer sciences or by a Human Computer Interaction researcher, specialized in gerontechnologies. The questions asked to each resident related to his or her motivation to come and live in a shared house, living conditions before and after joining the shared house, health profile, integration, feedback, potential improvements of the shared home, weaknesses of this type of housing and the means to avoid them, his or her knowledge of technologies, attitude towards technologies. The interviewers were open to expectations, motivations, refusals...

The focus group was based on the common experience of using the shared house and took into account the results of the semidirective interviews. A summary of these results was presented for discussion. The focus group was carried out with the five participants who had agreed to be filmed. It was conducted by a researcher trained in focus groups with elderly people with disabilities.

\subsubsection{Interviews and discussion with the assistant}

The semi-directive interviews were carried out by two researchers in ICTs (Information Communication Technology). They took place face to face with each of the two assistants and lasted about 45 minutes each. The questions related to 3 main themes:

- The role of the assistants and their own vision of the contribution of a shared home. They were also asked to talk about the requirements for their position. In order to do so, they were asked to describe their daily routines.

- The needs of the assistants in terms of assistive tools (technical, technological, human...) and when they would need them. They were also asked to imagine a connected shared house.

- The way in which exchanges between residents and assistants occur (means of communication, types of exchanges, and types of solicitations...) but also with people's relatives, with health professionals, with home care services and the relationships between the different residents.

Both define their role as multifaceted: mediator, companion, supervisor, counsel, advicer, helper, sometimes psychological support (during periods of "depression" or "anxiety").). One of them says "I feel at home when I am in the shared house, in a common place, with people who are part of my family". Both define the inhabitants as "pleasant people who have found their place in a group, with the desire to keep or recover a social life and security". Solidarity and organization of the group of residents are established fairly quickly according to the physical, intellectual or manual capabilities of the occupants. None of the residents is expressing the wish to enter a nursing home. One of the two assistants expresses the interest, by her point of view, of living well in a group, the importance of recovering social links, and the degree of privacy that the inhabitants should retain (i.e. their own bedroom). Both believe that it is not necessary to "do instead of" the residents. It is more important to encourage them to do by themselves or be present when required (tying shoes, carrying objects, help at time to go to bed). They consider that $70 \%$ of their working time is for people, and $30 \%$ for household tasks.

The time devoted to residents includes, for example, the solicitation for outings, organizing collective tasks where everyone has to take their part according to their competence, desires or wishes (taking meals together, preparing meals and cleaning the table, washing up...). In terms of home automation installations or equipment, they mention dysfunctions in the motorized work-top, untimely activation of lighting or poor positioning of telephones in the rooms. 
Following the interviews with the assistants and the focus groups, we got a preliminary idea of potentials needs and prospect technologies. We proposed the residents to come with their assistants to the Blagnac smart home a week later. They would get the opportunity to try some technologies that could be of interest to them and discuss on their relivence in the shared house.

\subsection{Experimentation and focus group within the Blagnac smart home}

\subsubsection{Description of the Blagnac smart home}

The Blagnac smart home is a Living Lab-type technology platform used for the design and assessment of health and home support technologies (Figure 3). This platform is showing a good sample of existing technological solutions to achieve home security, comfort, communication and assistance, for the disabled people, with a special focus on disability in the senior population. These technologies include sensors for measuring ambient parameters or for domestic safety, assistance devices (pillboxes, automatic lighting, guidance systems, automated opening systems, etc.), fall detection and geolocation devices, mobility aids, motorized furniture (adjustable in height), etc. A Wizard of Oz type platform [13] allows participants to experience voice control when it is not actually implemented for a said functionality.

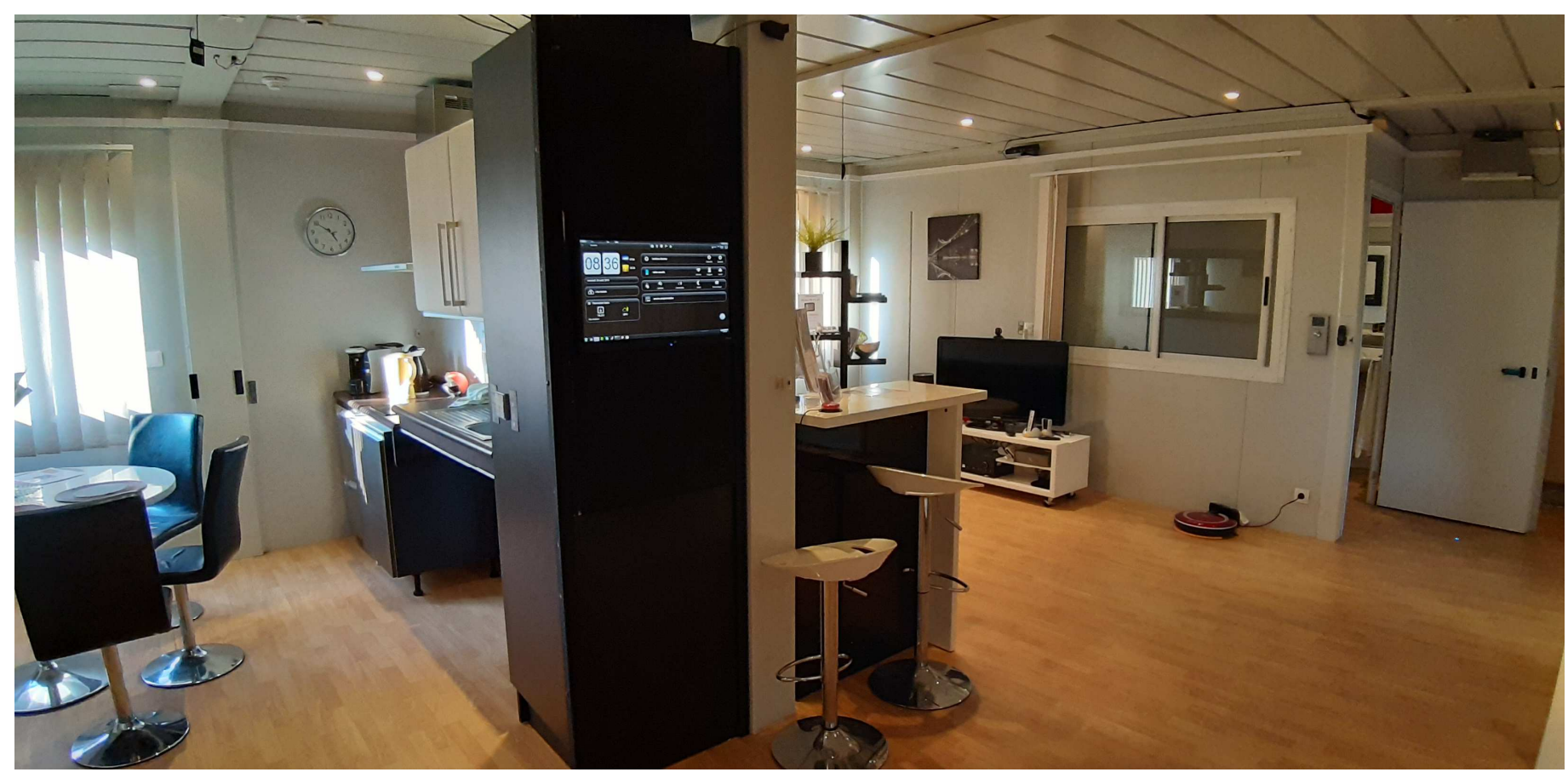

Figure 3. The Blagnac smart home.

\subsubsection{Visit of the Blagnac smart home and performing of a morning rise by the residents of the Montredon house}

The three residents and the assistants got a joint visit of the place and features. The researchers who had carried out the interviews in the Montredon shared house were the same who guided the visit. The demonstration consisted in presenting home automation functions: opening the shutters, turning on the light, adjusting the height of the sink and controlling the television using three interaction modes (push buttons, tactile interaction (See Figure 4) and voice control [13] and [14]). 


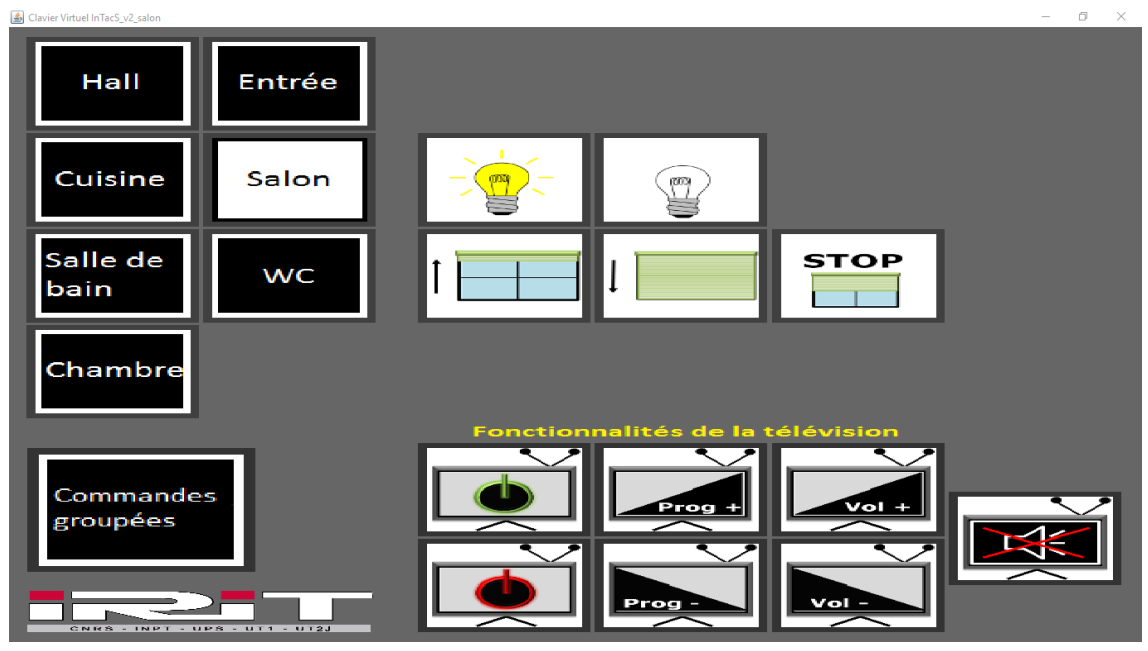

Figure 4. The tactile interface InTacS.

After the demonstration, the residents performed a scenario of getting up and having breakfast, then a scenario of television use. The touch controls were in real operation, the voice control was simulated by a Wizard of Oz. The starting point of the scenario was given by a researcher, the end was decided by the volunteer when he or she considered the task completed or failled.

\subsubsection{Focus Group with the residents}

For this second focus group (See Figure 6), we had decided to integrate the assistants (as intermediate users who could have an impact on the fulfiment of the needs of the residents and as observers of the needs of the residents), after a first phase carried out only with the residents. The focus group was led by the same facilitator as the one carried out in the shared habitat of Montredon, i.e the geriatrician.

\section{Results}

\subsection{Description of the study population}

The 6 residents (See Tab. 2) and the two assistants participated in the first phase of the study within the shared housing. One of the residents did not want to be filmed and therefore did not take place in the focus group. Among the five residents who took place in the study, two were unable to travel to the Blagnac smart home.

The average length of time of the interview was about one hour for each inhabitant. The interviews allowed to define the population of the Montredon shared house: 90 years old on average, from the local community, with a low average level of education (primary or secondary). They are all widowers, have low incomes - when these have been reported (850 to $1400 € /$ month). The sex ratio is $2: 1$ in favour of the ladies. Their autonomy is preserved in everyday life between 5.5 and 6 (ADL scale [15]), but their instrumental activities are altered to a median 2, ranging from 0 to 4 (IADL scale with a maximum of 8 points [16]). One person has only one descendant; the others have 8 to 17 descendants.

Two people have frequent contacts both by telephone and visits, three say they have rare contacts outside the home and one talks about contacts inside the shared home only (cognitive impairment can influence this result). The use of technology, as defined by the persons, remains limited: four use those technologies to communicate (phone) or as a medium (television), one to communicate only (says "having abandoned television and the computer"), and one only as a medium (she says "no longer using the telephone"). The mobile phone is the most widely used tool: four out of six people use it. Three persons spontaneously report difficulties in using the telephone at various levels, related to understanding how it works.

\section{2. $\quad$ Needs expressed by residents during interviews}

During the interviews, the participants expressed limited needs. The telephone is the main topic. A person talks about its complexity, says he only uses pre-recorded numbers or picks up. Another says that she had "an indigestion" with the phone. A fear was expressed, about difficulties in learning to use new technologies: one resident mentionned the "too complex phone", another says it is "too hard". Information and communication technologies can even be perceived as potentially dangerous: "the harmful aspect of the waves emitted by new technologies". 
Voice control is not considered as realistic and is related to very complex service requests: "It's five minutes to noon, bring me the soup. I went to a dirty place: wax my shoes." The only technologies spontaneously mentioned were the thermostat or automatic light, through the description of malfunctions.

When asked what one would like to have in the shared house, four answer: "nothing", one: "two more drawers" and one: "that my grandson finds a job". Technologies do not spontaneously come to mind.

Tab. 2. Participants characteristics.

\begin{tabular}{|c|c|c|c|c|c|c|}
\hline \multicolumn{7}{|l|}{ Participants } \\
\hline Characteristicss & $L R A$ & $M B E$ & $R D E$ & GMA & OLA & PBO \\
\hline Steps performed & Montredon & Montredon & $\begin{array}{l}\text { Montredon + } \\
\text { MIB }\end{array}$ & Interview & $\begin{array}{l}\text { Montredon } \\
+ \text { MIB }\end{array}$ & $\begin{array}{l}\text { Montredon } \\
+ \text { MIB }\end{array}$ \\
\hline Origine & $14 \mathrm{~km}$, rural & $0 \mathrm{~km}$, rural & $23 \mathrm{~km}$, rural & $21 \mathrm{~km}$, urban & $20 \mathrm{~km}$, rural & $27 \mathrm{~km}$, rural \\
\hline Age & 87 & 96 & 90 & 91 & 90 & 82 \\
\hline Gender & $\mathrm{M}$ & $\mathrm{F}$ & $\mathrm{F}$ & $\mathrm{F}$ & $\mathrm{F}$ & M \\
\hline School evel & II & I & I & II & II & II \\
\hline Profession & $\begin{array}{l}\text { Senior } \\
\text { executive }\end{array}$ & Worker & At home & At home & $\begin{array}{l}\text { Office } \\
\text { worker }\end{array}$ & Executive \\
\hline Declarative income $\mathrm{k} €$ & 1.4 & 0.85 & 0.9 & Don't know & Don't know & No filled in \\
\hline Marital status & Widower & Widower & Widower & Widower & Widower & Widower \\
\hline Living children & 4 & 1 & 3 & 5 & 1 & 1 \\
\hline Little children & 10 & 4 & 4 & 7 & 2 & 0 \\
\hline Rear grand children & 3 & 5 & 6 & 5 & 5 & 0 \\
\hline Contact modalities & Visit, phone & Visit, phone & Nil & Visit, phone & Visit & Visit, phone \\
\hline Frequency of contacts & $* * *$ & $* * *$ & 0 & $* *$ & $*$ & * \\
\hline Reported deficiencies & $\begin{array}{l}\text { Hearing, } \\
\text { mobility }\end{array}$ & $\begin{array}{l}\text { Hearing, } \\
\text { vision, } \\
\text { mobility }\end{array}$ & Mobility & $\begin{array}{l}\text { Hearing, } \\
\text { mobility, } \\
\text { manipulation }\end{array}$ & $\begin{array}{l}\text { Hearing, } \\
\text { vision, } \\
\text { cognitive, } \\
\text { mental }\end{array}$ & Mobility \\
\hline ADL (Katz, [15]), 0 à 6 & 6 & 5.5 & 5.5 & 5.5 & 6 & 5.5 \\
\hline $\begin{array}{l}\text { IADL (Lawton, [16]), } 0 \\
\text { à } 8\end{array}$ & 2 & 2 & 2 & 2 & 0 & 4 \\
\hline Technology & media, phone & media, phone & media, phone & com. & media & $\begin{array}{l}\text { media, } \\
\text { phone }\end{array}$ \\
\hline
\end{tabular}

\subsection{Needs expressed by participants during the focus group conducted within the shared} house

This focus group (Figure 5) showed a mistrust of technologies and a criticism of technologies about their lack of robustness (light path and thermostat) or relevance (sink at variable height, a dishwasher is preferred). The content of the television programmes watched was described: news, weather forecast, TV games, and broadcasts about old songs or old films. There was no real firm demand for innovative interaction. The inhabitants are very suspicious of new technologies and want "things" that are very easy to use.

\subsection{Experimentation and focus group in the Blagnac smart home}

\subsubsection{Visit and performing scenarii by the residents of the Montredon shared house}

The visit to the MIB prompted many questions and thoughts from the residents of the Montredon shared house and the assistants: the possibility of getting up from the sofa, better readability of the interfaces, particularly the size of the interaction device and the size of the objects displaid on the user interface, the need for a voice remote control of the television "it would be good with the voice", the interest of not beeing equiped with an embedded sensor. Then, each resident, helped by one of the Blagnac smart home researchers, discovered the use of the touch application on the tablet [14] to control the smart home. All the volunteers managed to achieve commands (such as turning on the light or opening the shutters). The three volunteers then performed the scenario of a morning rise. Audio messages (i.e.: information about unavailable services, action to be taken by the resident, request for confirmation of the order) from the house's text-to-speech system were not understood or heard by two out of the three volunteers. Two of the three volunteers used voice mode to interact with the MIB. 


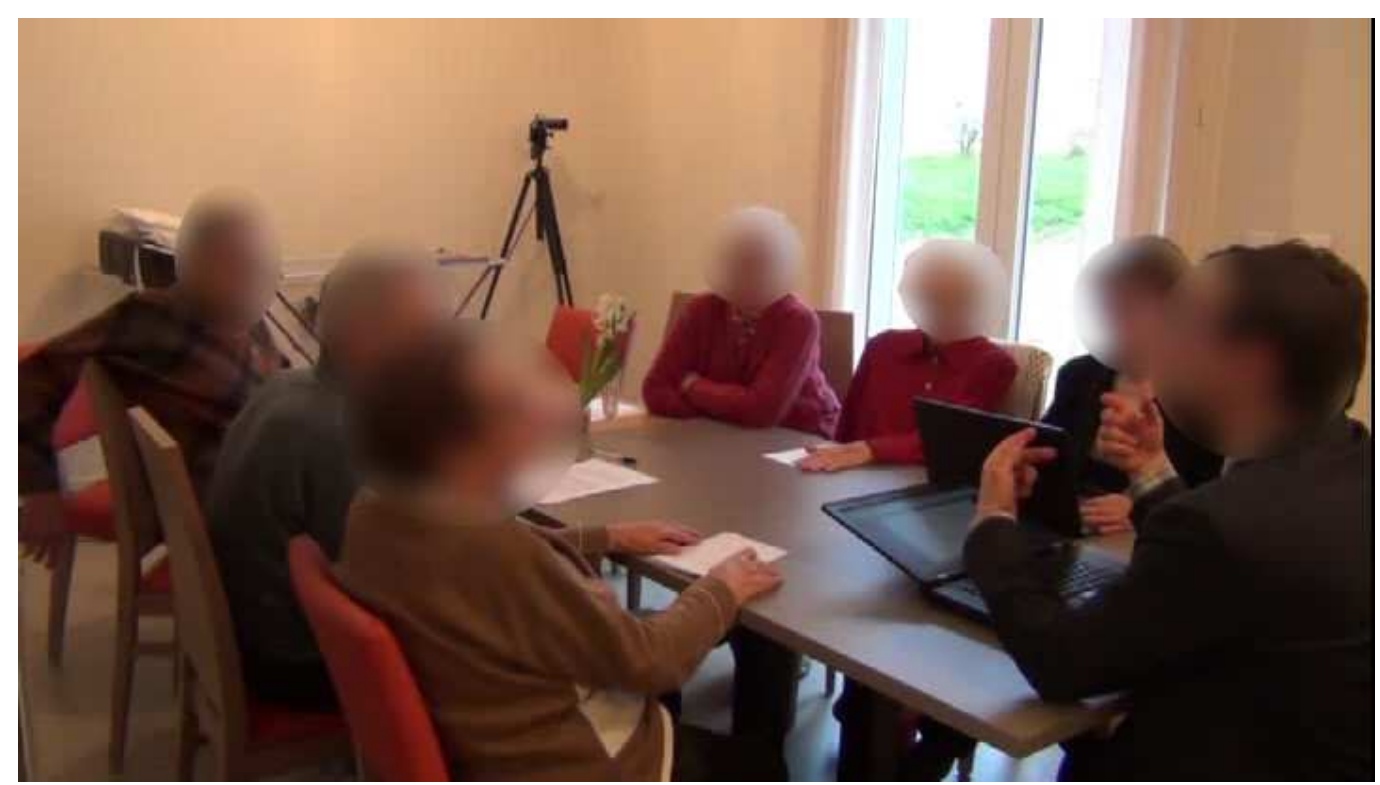

Figure 5. Focus group within the Montredon shared house (5 participants and focus group facilitator and session secretary).

\subsubsection{Focus group with the residents}

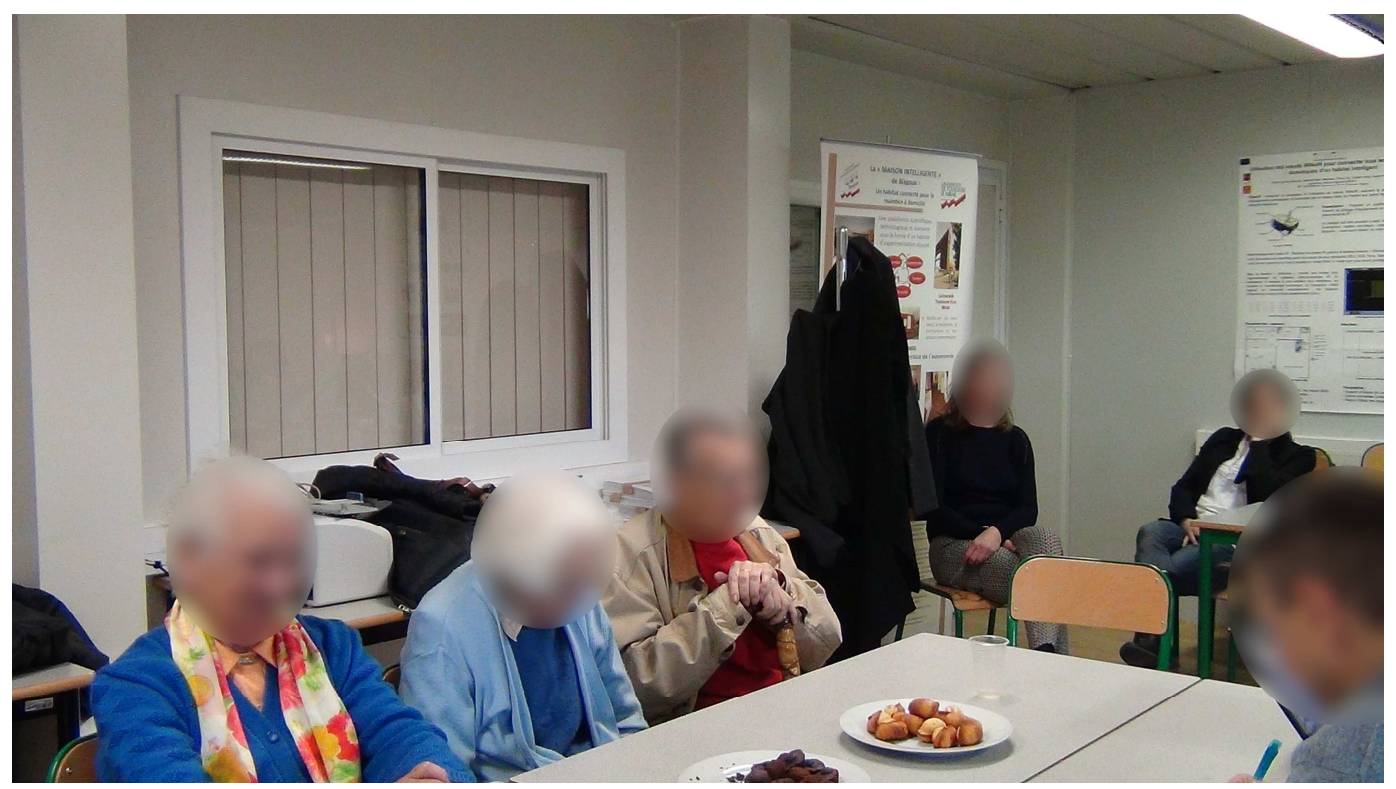

Figure 6. Focus group (3 participants) in the Blagnac smart home.

During the focus group at the Blagnac smart home (Figure 6), we noticed an evolution of participants' perceptions of the use of interaction techniques, including the voice interaction which use was presented in the scenario. Compared to the focus group held at the Montredon shared house, the discussion focused more on the tension between the physical action of the human being (resident) and that of the technique in terms of keeping fit. The risk that excessive ease of interaction could lead to conflicts between residents was also mentioned, as well as the important role of mediation of the assistants in maintaining the cohesion and harmony of the group. Consensus needs fall in four categories: 
- Security: compared to shared rooms, the bedroom is a source of anxiety: one fears to fall when alone. A call button in the bedrooms and a button for fall detection were mentioned several times. This need was identified in the focus group held with the residents and reported by the assistants. ${ }^{7}$

- Communication and stimulation: a computer to surf the Internet, a connected television to communicate with family and friends or interactive games such as "serious games".

- Mobility: the residents would like a wheelchair, to help people who fall or have difficulty moving because of pain.

- Thermal comfort: an easier management of the heating is desired. A wall-mounted touchscreen control interface is mentioned in which the heating control could be centralized (increase, decrease, stop, personal programming in private areas, common in collective areas).

Residents (and assistants) consider that the connected shared house would be an advantage. It would help the inhabitants and the assistants to manage the house but shouldn't assist the people too much.

\section{Discussion}

\subsection{Population}

The population of this shared house matches the demography of the elderly rural population with a predominance of women, linked to higher male mortality. It includes people of rural origin with low means and one person coming back to her geographical origins. The widowhood rate is age-related. It causes isolation, leading to join the shared housing. We notice that all residents have at least one disability: the most common is loss of mobility followed by loss of hearing. In a study carried out in the general population in Ile de France among people over 60 years of age, we find the same types of disabilities: motor disabilities (19\%) then hearing disabilities, and then visual and mental disabilities. The hearing loss rate we have noticed matches the statistics of $65 \%$ of people over 65 reported by INSERM ${ }^{8}$.

The well-performed activities of daily living confirm that this population is autonomous for basic activities. Instrumental activities show deficits in social participation that we can interpret as a decline in functional resources (International Classification of Functioning of WHO) or a frailty [18]. Therefore, we can assume that the population of Montredon is representative of the population over 65. Its particularity is to live in a shared habitat.

The uses of technologies are mainly focused on the media (information, entertainment) and communications (mainly with the family by videoconference). As far as communication, mainly with the family, is concerned, along with the desire to live in shared housing, we find the loss of friendly ties due to the death or disability of friends is a triger. Shared housing supports and even restores social cohesion through the organization of collective tasks and outings facilitated by the assistants.

Shared housing will therefore have to evolve to meet the security needs of residents and exchanges needs with the outside world via simple technologies accessible by the residents.

\subsection{Methodology}

Our method is similar to a cluster study on isolates (a shared home) with their own dynamics. At that feasibility stage we studied one only isolate: the shared home of Montredon. We have therefore a small number of participants. The reformulation method consensus or dissensus of the results of individual interviews (Montredon) or experiences (Blagnac) - in focus groups requires that the number of participants be limited due to their deficiencies. However, if the interviews allow deepening individual perceptions, the first focus group allowed identifying potential needs in a consensual way and in the respect of the natural dynamics of shared housing (community structure). After the second focus group and after the residents had performed the scenario and expressed their opinions, taking into account the open discussion with the assistants was natural because of their regulatory role in the dynamics of the shared house. We observed an attrition at the Blagnac stage of experiment (remote from the shared house). It was to be expected due to the population's disabilities and fragile health. Completing the group with people from another shared habitat, with potentially different dynamics was likely to introduce bias, it would have generated a breakdown in methodological coherence. Nevertheless, the remaining three participants were comparable in their distribution by gender, age, grade level, socio-professional category and type of disability to the total group.

\subsection{Results}

During the first part of our study, on site at Montredon, participants expressed the difficulty they experienced when trying to use ICT. This perception may be explained by the digital divide. Indeed, Youssef [17] identified four dimensions of the digital divide

\footnotetext{
${ }^{7}$ As part of an open discussion with the assistant after the focus group they attended without taking part, they expressed they would like to be reassured about people when they leave them in the evening for the night. A feeling of guilt was expressed about leaving people alone at night. A technological monitoring relay would be appreciated.
}

${ }^{8}$ INSERM: National Institute of Health and Medical Research 
centred on economic and social inequalities, one of which is linked to the use of ICT (Information and Communication Technology). The same author identified several factors explaining the use-related digital divides, including people's cognitive abilities as a blocking element limiting use. Indeed, the level of information and knowledge of digital technologies (Internet in particular and use of English language) would be a determining factor in their use.

When we see the evolution of sensed needs during the collection, it appears that the assessment, at the place of living, makes it possible to identify potential needs based on the residents' lifestyle and perceptions. The feedback on the inadequacies of technologies already deployed is not censored: neither on the difficulties of use nor the level of interest. However, unsurprisingly, we notice a difficulty for residents and assistants alike to project themselves into requests for services based on technological tools they do not know ("no" answer or answers inspired by remembrance of movies). The materialisation of use situations in the form of open scenarios within the framework of the Blagnac smart home made it possible, during the second focus group, to specify four types of needs. These needs, as perceived by the residents, were questioned and clarified by the assistants, in their role as group coordinators.

Security and communication needs could have been expected from the characteristics of family isolation and disability of the residents. The study allowed a more precise definition of the need for security: essentially at night, with a need for communication between residents and with the outside world. The need to maintain mobility in the event of a life accident arised with the expectation of simple low-tech solutions (wheelchair). A study of the activities carried out and their implementation could make it possible to identify additional aids (for example: facilitating wheelchair travel). Finally, thermal comfort has appeared with the distinction between collective and private areas, leading to the need for adapted interfaces. This need for comfort has also been identified as an opportunity to save energy and reduce costs.

\subsection{Towards True-Life Lab tools development}

The ecological function unit approach -or cluster- will allow comparisons between clusters, using a benchmarking method. Besides, we consider carrying out a lengthwise study, from people's current home up to their admission in a shared house, and the follow-up during a few months. This long-time follow-up will require continuous and autonomous measuring tools for behavior observations. To achieve this goal, we envision a True-Life Lab Box (TLLB), with mobile equipment, such as sensors, means of telecommunications, and a computer infrastructure, for the collection and the storage of data. The design of such generic experimental equipment raises several questions; the equipment will have to provide solutions to different problems encountered in various situations:

- How does one solve the problem of the great variety of tools which need to be connected in order to ensure interoperability of the devices?

- How does one solve the problem of a non-intrusive deployment within a person's home?

- How does one respect ethical issues and respect private life, in this context?

- How does one protect the collected data, which are exchanged and saved?

- How does one take into account the acceptability of devices and software tools for the users?

The ICT and human sciences researchers will focus on these issues.

\section{Conclusion}

The concept of shared house is an alternative way of living for frail elderly persons, or handicaped persons, particularly in rural areas. The methodology, for this first research, is based on an ecological function unit. The on-site phase enabled the researchers to identify parts of the needs and provided an initial consensus among the residents. In accordance with this consensus, a visit of a smart home -Living Lab type- was organized. It was followed by the performing of two scenarios. Then we concluded with alast focus group and open discussion with the participants. Our results give a bottom up approach of the needs of the elderly people and contextualize them through an active partnership with those concerned.

In that respect, we have avoided the two main weaknesses regarding expression of needs methodes regarding the potential users: on the one hand a poor understanding of the existing technologies and a lack of perceived needs (methods based on "on-site analysis" only), and on the other hand the induction of apparent needs, unconnected with a real environment (methods based on technical demonstrations in controled environment).

As a prospective, we plan to deploy this qualitative method with other residents of two other shared houses and to lead workshops on the discovery and creation of digital technologies. The practical results will be used as part of the wellbeing strategy of Âges Sans Frontière charity.

From a method point of view, we consider designing a way to avoid the delocation to the living lab by designing a portable demonstration set we could easily customize and deploy according to the results of the first needs expression stage and local conditions. 


\section{Acknowledgment}

We are thankful to the association Âges Sans Frontières, for giving us access to the shared house in Montredon, organizing the arrival of the co-tenants and the assistants to the Blagnac smart home and cooperating with us for an optimal collection of data.

\section{Conflict of interest statement}

There is no conflict of interest

\section{Role of the funding source}

This research did not receive any specific grant from funding agencies in the public, commercial, or not-for-profit sectors.

\section{References}

[1] Argoud D. De l'hébergement à l'habitat : une évolution ambigüe, Fond. Nationale de Gérontologie, « Gérontologie et société », vol. 34, n¹36, pp. 13-27, 2011, ISSN 0151-0193.

[2] Labit A., Habiter en citoyenneté et solidarité pour mieux vieillir, Gérontologie et société, vol. 38, n 149, pp. 141-154, 2016, ISSN 0151-0193.

[3] Vigouroux N, Boudet B, Vella F, Savoldelli M, Rumeau P. WELLFAR-E-LINK®: TRUE LIFE LAB TESTING OF A HOMECARE COMMUNICATION. Nonpharmacol Ther Dement 2012.

[4] Pitaud P., Solitude et isolement des personnes âgées. ERES, «Pratiques du champ social», 2007,272 pages. ISBN : 9782749202556. DOI : 10.3917/eres.pitau.2007.01. URL : https://www.cairn.info/solitude-et-isolement-des-personnes-agees--9782749202556.htm

[5] Clément S., Mantovani J. et Membrado M. , Du bon voisinage aux solidarités de proximité, Dans Solitude et isolement des personnes âgées (2007), pages 105 à 138.

[6] Campéon A., «Vieillesses ordinaires en solitude », Gérontologie et société, 2011/3 (vol. 34 / n 138), p. 217-229. DOI : 10.3917/gs.138.0217. URL : https://www.cairn.info/revue-gerontologie-et-societe1-2011-3-page-217.htm.

[7] Guedj J., Broussy L., Lafont A. K. Les personnes âgées en 2030, Etats de santé, démographie, revenus, territoires, modes de vie : portrait-robot de la génération qui vient, Les études de Matières Grises - \#1 - Septembre 2018.

[8] DREES Etudes et Résultats, 728000 résidents en établissements d'hébergement pour personnes âgées en 2015 Premiers résultats de l'enquête EHPA 2015, , $\mathrm{N}^{\circ} 1015$, Juillet 2017.

[9] Rosenfelder C.,Vieillir dans un habitat autogéré : la question du « vivre ensemble », « Gérontologie et société », vol. 39, n¹52, pp. 155-167, 2017, DOI: $10.3917 / \mathrm{gs} 1.152 .0155$

[10] Ancilotto F. Comment âges sans frontières peut-elle utiliser un concept innovant d'accueil pour personnes âgées pour développer des activités stratégiques reliées à son cœur de métier ? Master 2 Mention Management Spécialité, Gestion des Entreprises Sociales et de Santé, Année Universitaire 2014-2015, Université Toulouse 1, Institut d'Administration des Entreprises.

[11] Van den Bossche A, Gonzalez N, Val T, Brulin D, Vella F, Vigouroux N, et al. Specifying an MQTT tree for a connected smart home. Lect. Notes Comput. Sci. (including Subser. Lect. Notes Artif. Intell. Lect. Notes Bioinformatics), 2018. doi:10.1007/978-3-319-94523-1_21.

[12] Vella F, Blanc Machado M, Vigouroux N, Van den Bossche A, Val T. Connexion du Middleware MiCom avec l'interface tactile InTacS pour le contrôle d'une smart home. In 11emes Journées francophones Mobilité et Ubiquité ; 2016, support électronique.

[13] Vigouroux N, Van den Bossche A, Vella F, Campo E, Blanc Machado M, Val T. MIOZ: a Wizard of Oz platform to design ambient technologies. Recherche en Imagerie et Technologies pour la Santé ; 2015, p. 168-169.

[14] Bougeois E, Duchier J, Vella F, Machado MB, Van Den Bossche A, Val T, et al. Post-test perceptions of digital tools by the elderly in an ambient environment. Lect. Notes Comput. Sci. (including Subser. Lect. Notes Artif. Intell. Lect. Notes Bioinformatics), 2016. doi:10.1007/978-3-319-39601-9_32.

[15] Katz S, Ford AB, Moskowitz RW, Jackson BA, Jaffe MW. Studies of the illness in the aged. The index of ADL: a standardized measure of biological and psychosocial function. JAMA 1963; 21: 914-9.

[16] Lawton MP, Brody EM. Assessment of older people: Self-maintaining and instrumental activities of daily living. Gerontologist 1969. doi:10.1093/geront/9.3_Part_1.179.

[17] Youssef, A. B. Les quatre dimensions de la fracture numérique, Lavoisier | « Réseaux » 2004/5 n 127-128 | pages 181 à 209, ISSN 0751-7971

[18] Fried LP, Tangen CM, Walston J, Newman AB, Hirsch C, Gottdiener J, et al. Frailty in Older Adults: Evidence for a Phenotype. Journals Gerontol Ser A Biol Sci Med Sci 2001. doi:10.1093/gerona/56.3.m146. 